\title{
Conf- $950892--2$
}

Note: This is a preprint of a paper submitted for publication. Contents of this paper should not be quoted or referred to without permission of the author(s).

To be presented at the 53rd Annual Meeting of the Microscopy Society of

America, Kansas City, Missouri, August 13-17, 1995 and published in Proceedings

\section{Z-CONTRAST IMAGING OF CATALYSTS IN THE 300 KV STEM}

S. J. Pennycook and D. E. Jesson

Solid State Division, Oak Ridge National Laboratory

P.O. Box 2008, Oak Ridge, Tennessee 37831-6030

D. R. Liu

Ford Motor Company, Research Laboratory

20000 Rotunda Drive, Dearborn, Missouri 48121

"The submitted manuscript has been authored

by a contractor of the U.S. Govemment under

contract No. DE-AC05-84OR21400.

Accordingly, the U.S. Government retains

nonexclusive, royalty-free license to publish or

reproduce the published form of this

contribution, or allow others to do so, for U.S.

Government purposes."

Prepared by

SOLID STATE DIVISION

OAK RIDGE NATIONAL LABORATORY

Managed by

MARTIN MARIETTA ENERGY SYSTEMS, INC.

under

Contract No. DE-AC05-84OR21400

with the

U.S. DEPARTMENT OF ENERGY

Oak Ridge, Tennessee

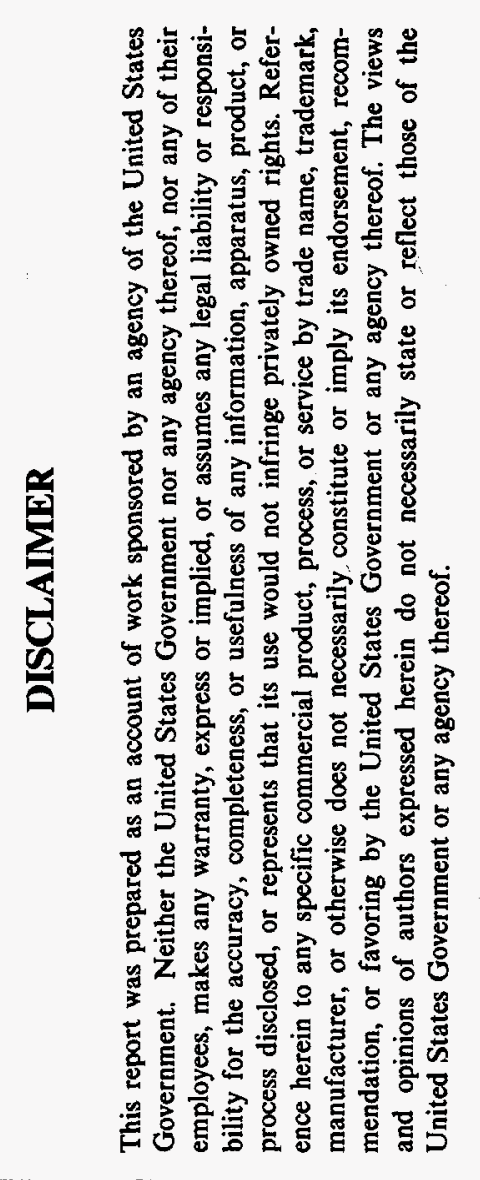

March 1995

DISTRIBUTION OF THIS DOCUMENT IS UNLIMITED $N^{N}$ 


\section{DISCLAIMER}

Portions of this document may be illegible in electronic image products. Images are produced from the best available original document. 


\title{
Z-CONTRAST IMAGING OF CATALYSTS IN THE $300 \mathrm{KV}$ STEM
}

\author{
S. J. Pennycook, D. E. Jesson and D. R. Liu*
}

Solid State Division, Oak Ridge National Laboratory, P.O. Box 2008, Oak Ridge, TN 37831-6030;

*Ford Motor Company, Research Laboratory, 20000 Rotunda Drive, Dearborn, MI 48121.

Z-contrast imaging in the scanning transmission electron microscope has become the accepted technique for imaging sub-nanometer catalyst clusters, utilizing the high angle annular detector introduced by Howie $^{1}$. The lack of coherent phase contrast effects greatly assists the identification of small clusters, especially near the resolution limit of the microscope ${ }^{2}$. The choice of inner detector angle depends on the system being studied. The highest signal to noise ratio is obtained with the smallest inner detector angle, but increasing this angle significantly reduces the contribution of coherently scattered electrons, which is advantageous for crystalline support materials. In this case, small metal clusters may be unambiguosly distinguished from diffracting regions of the support, and their size distributions determined. Fig 1 compares two preparations of $1 \mathrm{wt} \% \mathrm{Pd}$ on $\gamma-\mathrm{Al}_{2} \mathrm{O}_{3}$, prepared from palladium nitrate solution ${ }^{3}$, and aged at $600^{\circ} \mathrm{C}$ for (a) 6 hours, and (b) 24 hours. Images were taken with a VG Microscopes HB501UX 100 $\mathrm{kV}$ STEM, using a probe size of $\sim 3 \AA$. The narrower size distribution resulting from the longer aging time is clearly observed.

Now that cluster sizes are approaching the resolution limit of $100 \mathrm{kV}$ instruments, we might anticipate significant advantages in utilizing the smaller probes available with a $300 \mathrm{kV}$ STEM. Although for size distibution determination we may not require the $1.3 \AA$ probe available with this instrument, two potential advantages are immediately apparent. Since the clusters are supported on high surface area support materials, which are naturally three dimensional in form, the microscope depth of focus and the degree of beam broadening in the support are critical considerations. Probe profiles as a function of defocus are shown in Fig. 2. At $300 \mathrm{kV}$, although the optimum probe profile is much sharper than at $100 \mathrm{kV}$, the loss of intensity at low defocus values, and the extended tails at high defocus values mean that for a probe size of $\sim 2.5 \AA$ the depth of focus is limited to $\sim 800 \AA$ in both cases. However, the $300 \mathrm{kV}$ STEM does offer a substantial reduction in beam broadening. Particles on the exit surface of the support will be imaged with a probe that has undergone beam broadening (assuming that no strong channelling condition exists in the support). The thickness dependence of the spatial resolution calculated by the simple formula of Goldstein et. al. ${ }^{4}$ is plotted in Fig. 3. Since beam broadening is inversely proportional to accelerating voltage, for a $300 \mathrm{kV}$ probe, $3 \AA$ resolution can be expected after passing through $200 \AA$ of support, but this reduces to less than $100 \AA$ for a $100 \mathrm{kV}$ probe. Evidence of this increased penetration power is seen in the image of Fig. 4a., taken with the VG Microscopes HB603. For comparison, Fig. 4b. shows a bright field phase contrast image, recorded simultaneously, in which no catalyst clusters can be discerned.

In the future it may prove possible to resolve the atomic structure of real catalyst clusters by utilizing the small probe capability of the $300 \mathrm{kV}$ STEM. For sufficient signal to noise ratio it would be necessary to reduce the detection angle to the minimum necessary for incoherent imaging ${ }^{5}, \theta_{i}=1.22 \lambda / \Delta R$, or $\sim 12$ mrad for a $2 \AA$ column spacing. Transverse incoherent imaging would then allow column positions to be determined directly from the image. However, since the image would be formed from coherently scattered electrons, the intensity of each column would be proportional to the square of the number of atoms in the column, up to a thickness of $2 \lambda / \theta_{i}{ }^{2}$ after which scattering from the top and bottom of the crystal destructively interfere. For a $12 \mathrm{mrad}$ inner detector angle this thickness is $267 \AA$, well above the thickness range of interest. Therefore it should be possible to use maximum entropy image analysis to quantify positional and intensity information, and extract the likely three-dimensional form of the cluster ${ }^{6}$.

\section{References}

1. A. Howie, J. Microsc. 117 (1979) 11.

2. M. M. J. Treacy and S. B. Rice, J. Microsc. 156 (1989) 211.

3. D. R. Liu et. al. , these proceedings. 
4. J. I. Goldstein et. al. SEM/1977, 1, ed O. Johari, IITRI, Chicago, Il.,p315.

5. D. E. Jesson and S. J. Pennycook, Proc Roy Soc Lond A441 (1993) 261.

6. This research was sponsored by the Division of Materials Sciences, U.S. Department of Energy, under contract DE-AC05-84OR21400 with Martin Marietta Energy Systems, Inc.
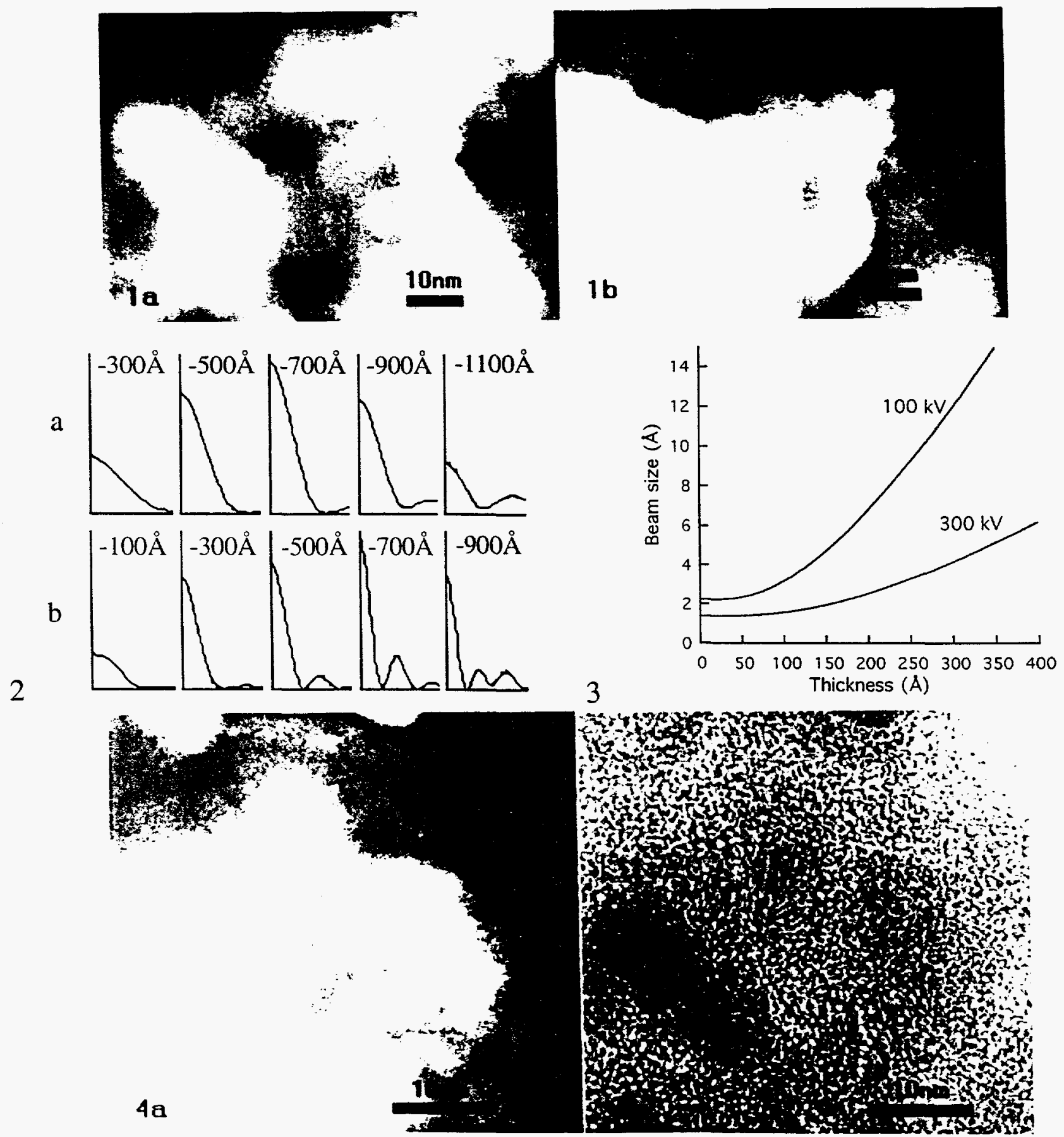

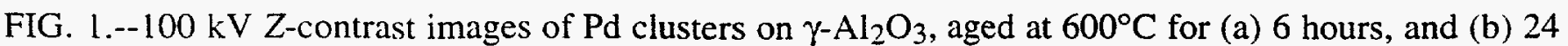
hours. FIG. 2.--Probe profiles as a function of defocus at (a) $100 \mathrm{kV}, \mathrm{C}_{\mathrm{s}}=1.3 \mathrm{~mm}, 10.3 \mathrm{mrad}$ aperture, and (b) $300 \mathrm{kV}, \mathrm{C}_{\mathrm{S}}=1 \mathrm{~mm}, 11.3 \mathrm{mrad}$ aperture. Fig. 3.--Beam broadening in $\gamma-\mathrm{Al}_{2} \mathrm{O}_{3}$. Fig. 4.--(a) 300 $\mathrm{kV} \mathrm{Z}$-contrast image of $\mathrm{Pd}$ clusters on $\gamma-\mathrm{Al}_{2} \mathrm{O}_{3}$, aged $600^{\circ} \mathrm{C}$ for 24 hours, (b) Simultaneous bright field image. 